\title{
DIAGNÓSTICO E CARACTERIZAÇÃO DA ARBORIZAÇÃO URBANA DE VIAS PÚBLICAS DA CIDADE DE ARAÇUAÍ, SEMIÁRIDO DE MINAS GERAIS
}

\author{
DIAGNOSIS AND CHARACTERIZATION OF URBAN AFFORESTATION OF PUBLIC \\ STREETS IN THE CITY OF ARAÇUAÍ, SEMI-ARID OF MINAS GERAIS
}

\author{
Anderson Almeida Silva ${ }^{1}$, Kaíque Mesquita Cardoso² $^{2}$
}

\begin{abstract}
RESUMO
Objetivou-se diagnosticar e caracterizar o estado da arborização urbana na cidade de Araçuaí, região Semiárida do nordeste de Minas Gerais, por meio de um levantamento florístico quali-quantitativo, utilizando formulário estruturado. Para avaliar a arborização urbana das vias adotou-se o inventário florestal por amostragem casual estratificada, agrupando 32 bairros em 9 setores. As unidades amostrais foram compostas pelos quarteirões (171), os quais foram selecionados e georreferenciados previamente à coleta de dados. Amostraram-se 1.090 indivíduos, distribuídos em 62 gêneros botânicos e 58 espécies entre árvores e arbustos, das quais $74,14 \%$ são exóticas, além de apresentar densidade arbórea abaixo do ideal. As espécies que apresentaram maiores abundâncias foram Azadiractha indica (30,73\%) e Licania tomentosa $(20,40 \%)$, ambas com percentuais que ultrapassaram o recomendado. No geral, os indivíduos possuem fitossanidade boa, predominância de circunferências maiores que 45 centímetros e alturas totais menores que 6 metros. A altura da primeira bifurcação e largura do passeio possui valores abaixo do recomendado. A condição da raiz é "boa", há percentuais significativos de copas em conflito com a fiação, além dos avanços de copa, tanto para rua quanto para a construção. Há necessidade de podas que variam de leves a drásticas em todos os setores.
\end{abstract}

Palavras-chave: Planejamento urbano; Inventário florestal; Azadirachta indica; Licania tomentosa.

\section{ABSTRACT}

The objective was to diagnose and characterize the condition of the street trees in the city of Araçuaí, semiarid region of northeastern Minas Gerais, carrying out a quali-quantitative floristic survey using a structured form. To evaluate the urban afforestation of the roads, a forest inventory was adopted by stratified random sampling, grouping 32 neighborhoods into 9 sectors. The sample units were composed of the blocks (171), which were selected and georeferenced before data collection. A total of 1,090 individuals were inventoried, distributed in 62 genera and 58 species among trees and shrubs, of which $72.40 \%$ are exotic, besides presenting an tree density below the ideal. The species that presented greater abundance were Azadiractha indica (30.73\%) and Licania tomentosa (20.40\%), both with percentages that exceeded the recommended. In general, the individuals have a good phytosanitary condition, a predominance of circumferences larger than 45 centimeters and total heights smaller than 6 meters. The height of the first bifurcation and the width of the ride have values below the recommended. The root condition is "good", there are significant percentages of crowns in conflict with the spinning, in addition to the advances of crowns, both for the street and for construction with good results and there is a need for pruning that varies from light to drastic in all sectors.

Keywords: Urban planning; Forest inventory; Azadirachta indica; Licania tomentosa.

Recebido em 31.05.2020 e aceito em 10.12.2020

1 Tecnólogo em Gestão Ambiental. Graduando Licenciatura em Geografia (Centro Universitário Leonardo Da Vinci). Jaraguá do Sul/SC. E-mail: almeida.meioambiente@gmail.com.

2 Engenheiro Florestal. Doutorando em Agronomia (Fitotecnia). Professor do Ensino Básico, Técnico e Tecnológico - EBTT do Instituto Federal do Norte de Minas Gerais - IFNMG - Campus Araçuaí. Araçuaí/MG. E-mail: kaique.cardoso@ifnmg.edu.br. 


\section{INTRODUÇÃO}

A convivência em sociedade enfrenta inúmeros desafios, sendo um dos principais a manutenção da qualidade de vida nas áreas urbanizadas. Segundo o IBGE (2016), mais de 80\% da população brasileira vive em áreas urbanas. Com isto, há diversas problemáticas econômicas e socioambientais, como a favelização, aumento da criminalidade, desemprego, poluição de cursos d'água, desmatamento, entre outras, o que coloca em questão a capacidade que estas áreas têm de suportar de forma satisfatória todas as atividades humanas.

Discutir a temática da arborização urbana é essencial, pois a mesma influencia diretamente na qualidade de vida citadina. Segundo McPherson, Van Doorn e De Goede (2015), em estudo realizado na Califórnia, Estados Unidos, são retornados US \$5,82 aos cofres públicos para cada US \$ 1 investido no plantio de árvores, entretanto, no Brasil, há escassez de pesquisas de valoração econômica em relação ao investimento x retorno da arborização urbana.

O semiárido brasileiro se concentra na região nordeste e se estende até o norte de Minas Gerais, corresponde a $13,52 \%$ do território nacional. A cobertura vegetal dessa região é caracterizada principalmente por formações típicas denominadas de Caatinga ou Savana Estépica. São formações bem definidas, com mecanismos fisiológicos e anatômicos adaptados para a resistência à seca. Perdas de folhas durante a época de estiagem, troncos tortuosos, recobertos por cortiça e espinhos, bem como raízes que cobrem a superfície do solo fazem parte dessa paisagem (LACERDA; LIRA FILHO; SANTOS, 2011; ALVAREZ et al., 2012).

É importante que haja planejamento na implementação e manutenção da arborização urbana. No Semiárido por exemplo, torna-se imperioso, pois além das condições de clima quente e seco da região ser um ambiente hostil para o desenvolvimento de plantas, as florestas urbanas desempenham um serviço ambiental muito importante de regulação microclimática na cidade, o que reduz a radiação solar direta e aumenta o conforto térmico para populações, diminuindo ou mesmo inibindo a formação de ilhas de calor. (LACERDA; LIRA FILHO; SANTOS, 2011)

Outros serviços ecológicos fundamentais para a manutenção da qualidade de vida promovidos pela arborização são a diminuição da poluição sonora e do ar, redução do carbono atmosférico e atenuação da estética dos meios urbanos (MILANO; DALCIN, 2000; CARDOSO et al., 2017). Nesse sentido nota-se porque os bairros com maior predominância de áreas verdes são justamente os que possuem maiores valores de mercado (SOARES et. al., 2018).

A utilização de espécies exóticas à flora regional nas cidades agrava o processo de degradação dos fragmentos naturais (ALVAREZ et al., 2012), uma vez que a erosão genética pode fazer com que as espécies mais resistentes, mesmo que exóticas, sobressaiam sobre outras mais sensíveis, mesmo que sejam nativas de um determinado local. Deste modo, para se ter uma arborização eficiente e condizente com os aspectos ecológicos de uma região é necessário que haja planejamento nas ações. 
Com isso, uma das primeiras ações a serem desenvolvidas para um plano de arborização é a realização de um diagnóstico. No levantamento dos dados geralmente é realizado um inventário florestal, que tem como finalidade conhecer o patrimônio arbustivo e arbóreo de uma localidade (MELO; LIRA FILHO; RODOLFO JÚNIOR, 2007). Este levantamento fornece informações que definem as prioridades para futuras intervenções de manejo e manutenção.

Dessa forma, este trabalho teve como objetivo diagnosticar e caracterizar o estado da arborização urbana na cidade de Araçuaí, Minas Gerais, por meio de um levantamento florístico quali-quantitativo, com o propósito de destacar as principais problemáticas e perspectivas para um manejo apoiado no plano de arborização de uma cidade inserida no semiárido brasileiro.

\section{MATERIAL E MÉTODOS}

\section{Caracterização da área de estudo}

Realizou-se o estudo na cidade mineira de Araçuaí, situada na região nordeste do estado, na latitude $16^{\circ} 50^{\prime} 59^{\prime \prime} S$ e longitude $42^{\circ} 04^{\prime} 13^{\prime \prime}$ W. Incluída na região semiárida (Figura 1), o município conta com uma população de aproximadamente 36 mil habitantes, em uma área de $2.236,279 \mathrm{~km}^{2}$.
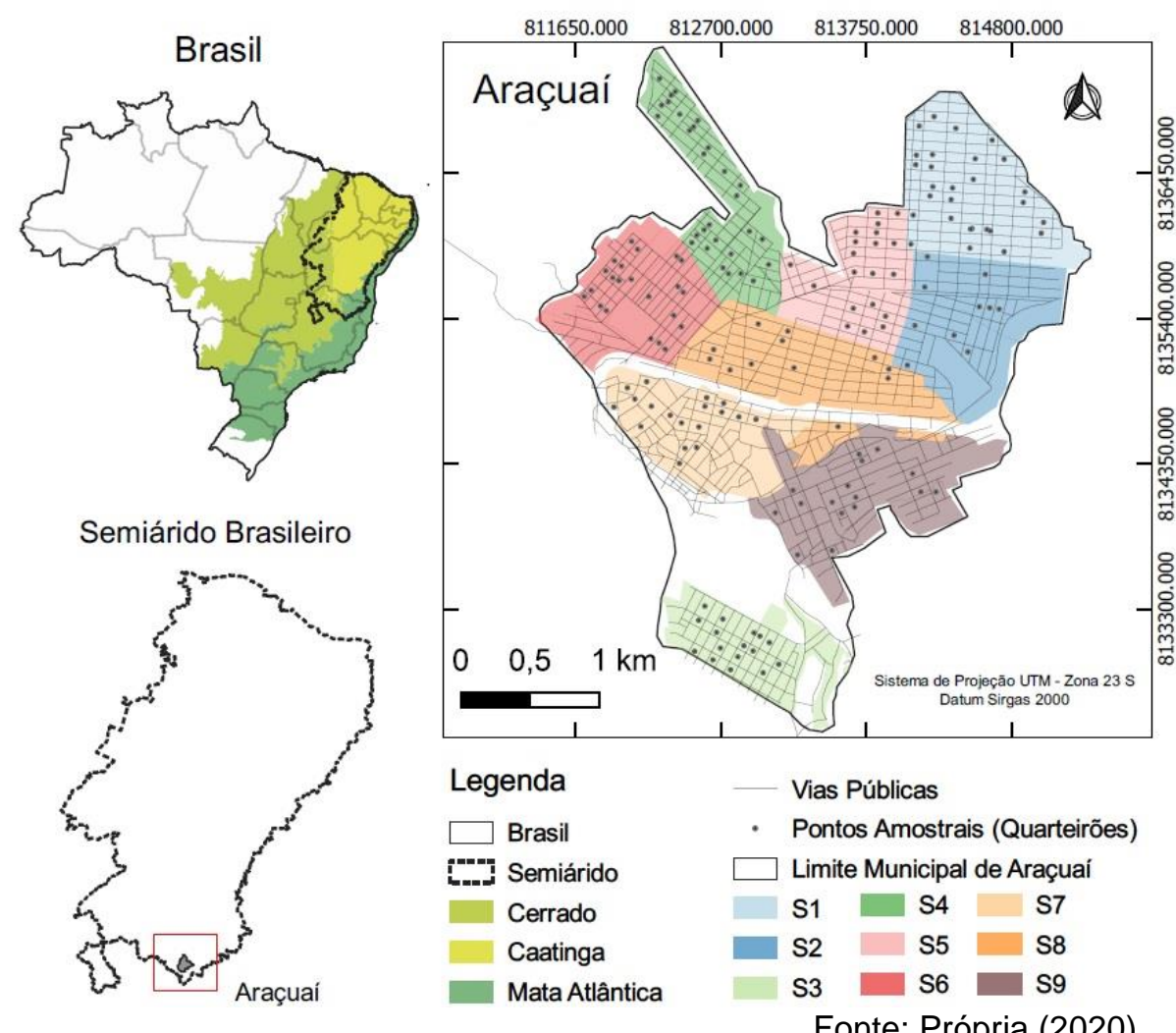

Figura 1. Mapa de localização da área de estudo, município de Araçuaí, no semiárido mineiro e a amostragem por estratificação dos setores, com os pontos amostrais em evidência.

Figure 1. Location map of the study area, municipality of Araçuaí, in the semi-arid region of Minas Gerais and sampling by stratification of sectors, with the sample points in evidence. 
$\mathrm{Na}$ classificação de Köppen, o município possui clima tipo AW, com inverno seco e estação chuvosa no verão. A precipitação da região atinge média anual de $766 \mathrm{~mm}$, concentradas de novembro a março, com a menor média mensal de $4 \mathrm{~mm}$ em junho e maior em dezembro com $164 \mathrm{~mm}$, sendo que a temperatura média mensal varia de 26,4 a 21,6 $\mathrm{C}$ (ALVARES et al., 2013). É notório que a região apresenta um período sazonal bem definido de seca e temperatura elevada durante todo o ano. Logo, a umidade relativa do ar e a evapotranspiração também são diretamente afetadas.

Araçuaí está incluída no zoneamento que delimita as cidades pertencentes ao semiárido, que é constituído principalmente pelo único bioma exclusivo brasileiro, Caatinga. O município está inserido em uma zona de transição (ecótono) que além da Caatinga, abriga o Cerrado e Mata Atlântica (OTONI, 2018).

\section{Amostragem}

Para avaliar a arborização urbana das vias da cidade adotou-se o inventário florestal por amostragem casual estratificada (SOARES; PAULA NETO; SOUZA, 2012). Para isso, criaram-se setores compostos pelos bairros da cidade, distribuindo um total de 32 bairros em 9 setores (Quadro 1). A estratificação dos setores foi definida com base no tamanho das áreas dos bairros, similaridade de malha viária e as respectivas localizações.

\begin{tabular}{|l|l|}
\hline Setores & Bairros \\
\hline S1 & São Francisco III \\
\hline S2 & São Francisco I; São Francisco II \\
\hline S3 & Nova Esperança; Mantegueira; Arraial \\
\hline S4 & Alto Paraíso; Cidade Jardim; São Pedro; Céu Azul; Fátima \\
\hline S5 & São Matheus; São Geraldo \\
\hline S6 & Canoeiro; Juparaná; Palmeiras; São José; Itatiaia; Renascença \\
\hline S7 & São Jorge; Centro; Alto Santuário; Alto Mercado \\
\hline S8 & Nova Terra, Grã-Bretanha, Vila Magnólia, Bela Vista; Jardim Nazareth \\
\hline S9 & Santa Tereza, Esplanada, JK; Vera Cruz \\
\hline
\end{tabular}

Quadro 1. Distribuição dos bairros em setores

Fonte: Própria (2020).

Chart 1. Distribution of neighborhoods in sectors

Com os setores definidos realizou-se a identificação das unidades amostrais em cada setor. Neste estudo, a metodologia utilizada é recomendada por Rachid e Couto (1999), onde cada quarteirão torna-se uma unidade amostral (UA). Para obtenção da suficiência amostral, realizou-se um Inventário Piloto (IP) por meio de sorteio aleatório de 10 UA (quarteirões) em cada setor. Utilizou-se a abundância de árvores (número de indivíduos por quilômetro de via) como 
variável principal. Com os resultados obtidos no IP determinou-se o número de parcelas definitivas, assumindo uma precisão de $20 \%$ e $5 \%$ de probabilidade de erro, dada pela equação 1 (SOARES; PAULA NETO; SOUZA, 2012):

$$
n=\frac{\boldsymbol{t}^{2} \cdot(\boldsymbol{C V})^{2}}{(\boldsymbol{E} \%)^{2}+\frac{\boldsymbol{t}^{2} \cdot(\boldsymbol{C V})^{2}}{N}}
$$

Onde $n$ representa o tamanho da amostra ou número de UA; $t$ o valor tabelado (distribuição Student), CV é o coeficiente de variação, $E$ representa a precisão requerida em porcentagem e $N$ o tamanho da população.

Para auxílio das ações de coleta de dados em campo foram georeferenciadas coordenadas geográficas (latitude e longitude) nas UA, a fim de que fosse possível o uso de aplicativos em dispositivos móveis (smartphones) como o Google Maps e Google Earth, ambos fornecem gratuitamente serviços de pesquisa e visualização de mapas em tempo real.

O aplicativo utilizado para obtenção das coordenadas geográficas foi o Fields Area Measure PRO (FAMP), versão 3.8.8, parcialmente gratuito, disponível na Play Store. Dessa forma, o pesquisador selecionava a UA desejada no FAMP, que por sua vez fornecia as coordenadas que eram lançadas no Google Maps / Google Earth, possibilitando o deslocamento preciso para a unidade amostral a ser inventariada. Para o levantamento quali-quantitativo utilizou-se um formulário estruturado com os seguintes quesitos: espécie; altura total; fitossanidade; altura da primeira bifurcação; largura do passeio; circunferência a altura do peito - CAP; condição da raiz; fiação conflitante; avanço da copa sobre a rua; avanço da copa sobre a construção e necessidade de poda.

\section{Coleta de dados}

A coleta de dados em campo foi realizada entre os meses de julho e setembro de 2019. Os aspectos foram avaliados com base em legendas que compunham o formulário. As espécies foram identificadas quanto à origem em relação à flora brasileira com validação pelo banco de dados do Flora do Brasil (2020).

O tamanho dos indivíduos foi medido de forma visual, adotando o parâmetro da altura dos postes de iluminação pública, os mesmos possuem altura entre 9 e 12 metros. As medidas da altura da primeira bifurcação $(m)$, largura do passeio $(m)$, circunferência a altura do peito (CAP) (cm) e avanço da copa sob a rua foram medidos por meio de diastímetro (fita métrica e trena), todos com legendas definidas. Os demais aspectos avaliados estão apresentados no Quadro 2. 


\begin{tabular}{|c|c|}
\hline \multicolumn{2}{|r|}{ Fitossanidade } \\
\hline Classes & Definição \\
\hline Boa & $\begin{array}{l}\text { indivíduo que aparentava estar vigoroso, sem sinais de doenças e bom } \\
\text { estado mecânico }\end{array}$ \\
\hline Regular & alguns sinais de doenças e leves danos mecânicos \\
\hline Ruim & $\begin{array}{l}\text { indivíduo no geral com estágios avançados de doenças/pragas e com } \\
\text { danos graves na parte física, como galhos em potencial de queda }\end{array}$ \\
\hline Morta & indivíduo em estado irreversível de recuperação \\
\hline \multicolumn{2}{|r|}{ Condição da Raiz } \\
\hline Classes & Definição \\
\hline Boa & raiz não exposta \\
\hline Regular & raiz exposta, mas sem causar trincas no meio físico que a cerca \\
\hline Ruim & raiz exposta e provocando trincas no meio físico que a cerca \\
\hline \multicolumn{2}{|r|}{ Avanço da copa sobre a construção } \\
\hline Classes & Definição \\
\hline Bom & copa não toca a construção. \\
\hline Regular & copa toca a construção, mas não apresenta riscos maiores \\
\hline Ruim & copa entrelaça com a construção com potencial de comprometer \\
\hline \multicolumn{2}{|r|}{ Relação Fiação x Copa } \\
\hline Classes & Definição \\
\hline Não possui & não há presença de qualquer fiação no local onde se encontra o indivíduo \\
\hline Acima & fiação se encontra acima da copa \\
\hline Abaixo & fiação se encontra abaixo da copa \\
\hline Meio & fiação se encontra no meio da copa \\
\hline \multicolumn{2}{|r|}{ Necessidade de poda } \\
\hline Classes & Definição \\
\hline Não & $\begin{array}{l}\text { indivíduo não necessita de poda, ou seja, copa aparentava estar bem } \\
\text { definida e sem avanços sobre a rua ou construção, bem como não } \\
\text { apresentava conflito com a fiação }\end{array}$ \\
\hline Leve & indivíduo necessita de leve poda de condução/manutenção \\
\hline Pesada & necessidade de poda pesada para adequar o meio físico do indivíduo \\
\hline Drástica & $\begin{array}{l}\text { indivíduo necessita de poda drástica devido estar em situação de risco } \\
\text { eminente para si e para todo o meio que o cerca }\end{array}$ \\
\hline
\end{tabular}

Quadro 2. Aspectos avaliados, com as classes e respectivas definições.

Fonte: Própria (2020).

Chart 2. Aspects assessed, with classes and respective definitions.

\section{Análise e interpretação de dados}

Os dados coletados foram tabulados em uma planilha eletrônica. Utilizaram-se os softwares Minitab® 19 Statistical e o SPSS Statistics versão 22 para a realização dos testes estatísticos.

Para analisar a aderência à distribuição normal, submeteram-se os dados ao teste de Anderson e Darling a 5\% de probabilidade de erro. O teste estatístico de Friedman a 5\% de probabilidade de erro foi adotado para comparação entre os grupos de dados. Representações gráficas foram construídas com o objetivo de facilitar a interpretação.

Os aspectos quali-quantitativos avaliados foram interpretados em duas formas de abordagem. A primeira (Primários) contempla os aspectos da altura total, fitossanidade, fiação conflitante e necessidade de poda de modo que haja apontamento para tomadas de decisão imediata e/ou curto prazo. Já a segunda abordagem (Secundários) contempla os demais aspectos (altura da primeira bifurcação, largura do passeio, circunferência a altura do peito CAP, condição da raiz, avanço da copa sobre a rua avanço da copa sobre a construção) que 
podem fundamentar no manejo de médio a longo prazo, de modo que auxilie em um planejamento estratégico.

\section{RESULTADOS E DISCUSSÃO}

\section{Densidade florística e espécies ocorrentes}

O universo amostral foi composto por 447 UA possíveis de análise, das quais, 171 fizeram parte do inventário definitivo. No total, amostraram-se 1.090 indivíduos, entre árvores e arbustos. $\mathrm{Na}$ Figura 2 são apresentadas as densidades florísticas com a respectiva intensidade amostral em cada setor. Para a SBAU - Sociedade Brasileira de Arborização Urbana, o número ideal de árvores por quilômetro de calçada-via é de pelo menos 100 indivíduos. Com base nisso, as vias da cidade de Araçuaí apresentaram resultados abaixo do ideal, de forma que nenhum dos setores alcançou ao menos metade do recomendado.

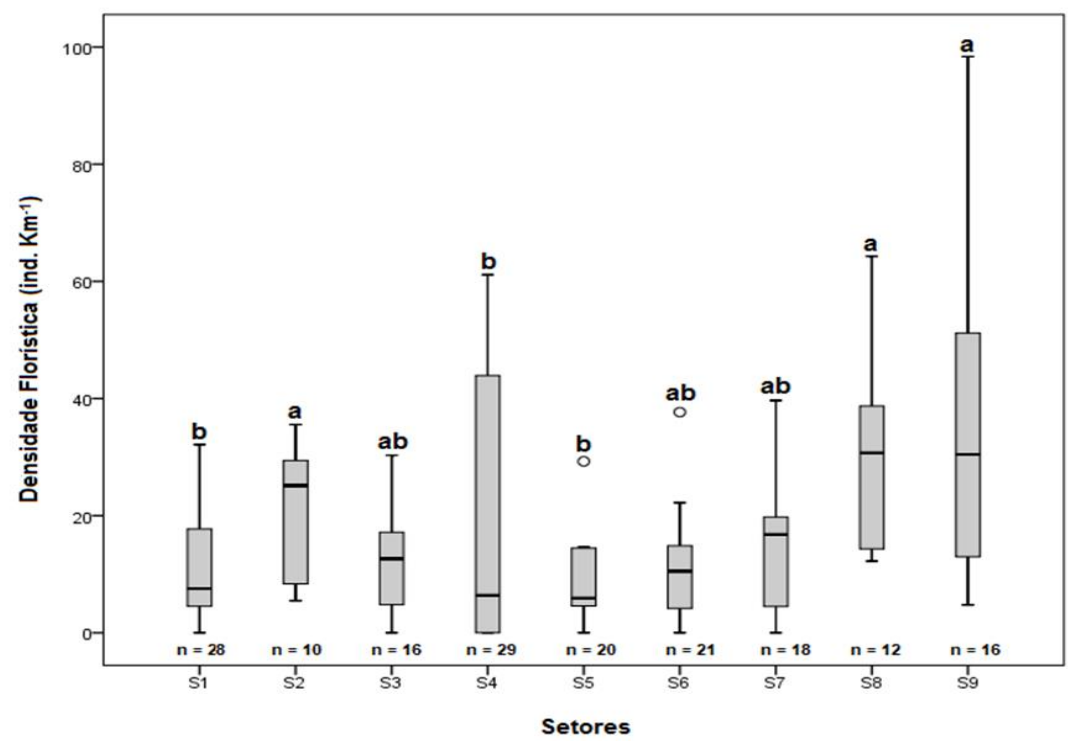

Figura 2. Box-plot da densidade florística das vias públicas de Araçuaí - MG, estratificado por setores, com o respectivo número de unidades amostrais (n). A linha horizontal interna das caixas representa a mediana, as extremidades das caixas representam o primeiro e terceiro quartil, os limites das barras verticais os valores máximo e mínimo. Medianas seguidas de mesma letra não diferem entre si pelo teste de Friedman a $5 \%$ de probabilidade de erro (comparação em pares, post-hoc)

Figure 2. Box plot of the floristic density of public roads in Araçuaí - MG, stratified by sectors with the respective number of sample units (n). The inner horizontal line of the boxes represents the median, the ends of the boxes represent the first and third quartiles, the limits of the vertical bars the maximum and minimum values. Medians followed by the same letter do not differ by the Friedman test at $5 \%$ probability of error (comparison in pairs, post-hoc.

O setor 9 (S9), foi o que apresentou maior densidade florística, com 34 ind $\mathrm{Km}^{-1}$ de via, seguido pelo setor 8 (S8) com 33 ind $\mathrm{Km}^{-1}$. Ambos os setores estão localizados em zonas centrais da cidade (Figura 3) e são compostos por alguns dos bairros que possuem maiores valores de mercado, como o Santa Tereza e Vila Magnólia, que notoriamente possuem 
residências de alto padrão construtivo, o que corrobora com SOARES et al. (2018), quando relaciona questões econômicas com a arborização urbana.

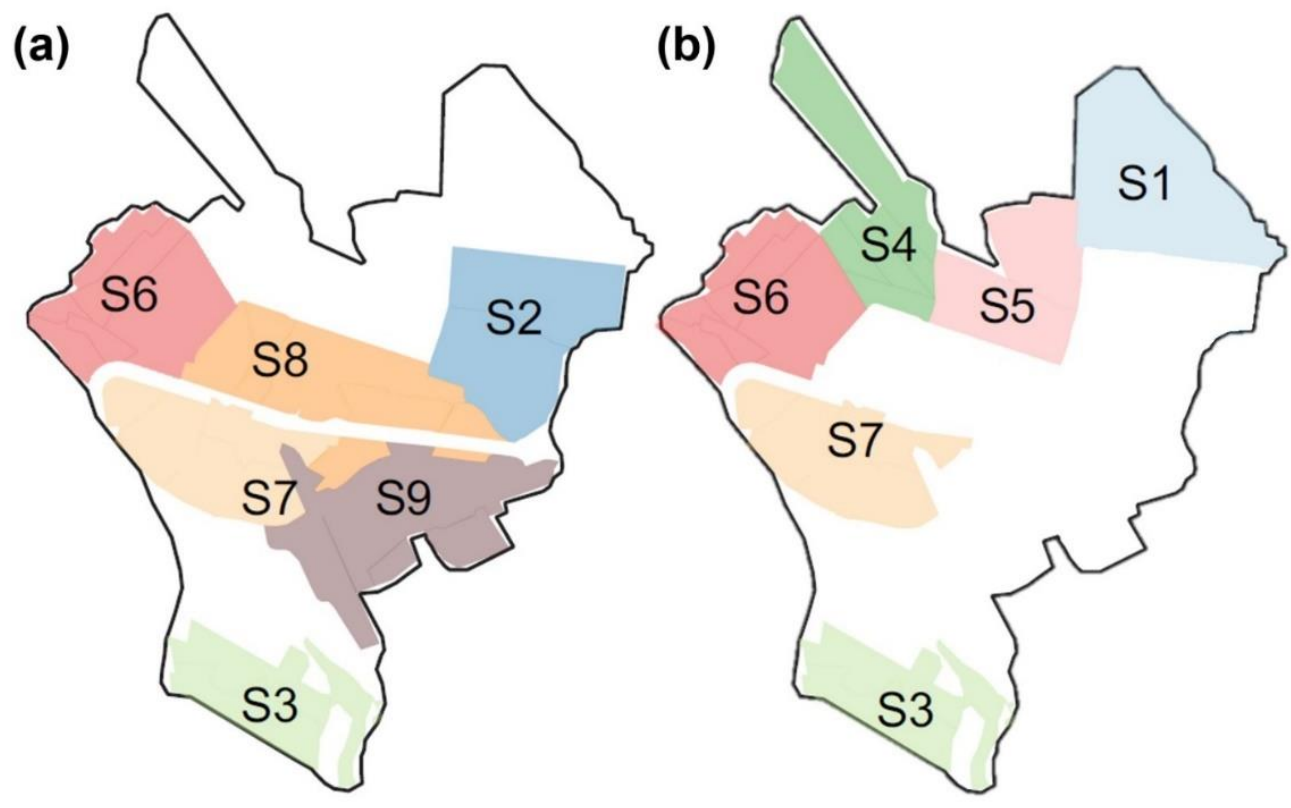

Figura 3. Setores agrupados por semelhança de densidade florística de acordo com teste de Friedman a $5 \%$ de probabilidade (Figura 2): maior densidade (a) e menor densidade (b).

Figure 3 . Sectors grouped by floristic density similarity according to the Friedman test at $5 \%$ probability (Figure 2): higher density (a) and lower density (b).

Entre os setores que possuem as maiores densidades florísticas, o S9 possui maior amplitude de distribuição dos dados. Essa variação representa uma heterogeneidade entre os bairros do setor, com valores máximos próximos ao recomendado pela SBAU. Os bairros que integram este setor se configuram como um dos loteamentos mais especulativos da cidade no aspecto imobiliário (Santa Tereza, Esplanada, JK e Vera Cruz), bem como alguns bairros do setor 8 (Vila Magnólia, Grã-Bretanha e Bela Vista). Portanto, o fator econômico pode influenciar a espacialização das áreas verdes do município.

Os setores S5 e S1 apresentam as menores densidades, estão localizados em zonas mais periféricas da cidade, com números dez vezes abaixo do ideal (6 ind $\mathrm{Km}^{-1}$ e 8 ind $\mathrm{Km}^{-1}$, respectivamente). Estas baixas densidades podem ser explicadas devido à falta de planejamento da arborização urbana destes setores aliado ao tipo de padrão construtivo dos imóveis, além de evidenciar a discrepância da carência de atenção de políticas públicas socioambientais em bairros compostos de classes social de menor poder aquisitivo.

Os demais setores obtiveram densidades florísticas entre 10 e 22 ind $\mathrm{Km}^{-1}$ de via, números que expressam um resultado indesejável da arborização de vias da cidade. Ressaltamse nestes setores os bairros como o Centro e o Canoeiro, os quais estão entre os bairros mais antigos da cidade, e ainda assim integram setores com resultados insatisfatórios. 
Percebe-se que os setores identificados com a mesma letra são similares, uma vez que não se diferem estatisticamente entre si. As maiores densidades florísticas se encontram nos setores S8 e S9 e as menores entre os setores S1, S4, S5 e S6. Os setores S2, S3 e S7 possuem valores de densidade que não se diferem do padrão geral da cidade.

Não obstante, S5, constituído pelos bairros São Mateus e São Geraldo é o setor com menor variação e densidade florística entre as medianas, com aproximadamente seis indivíduos por quilômetro de via. Deste modo, priorizar a qualidade dos indivíduos presentes neste setor se faz necessário. Como este setor está localizado em áreas ainda em expansão de domicílios, a baixa densidade arbórea pode ser decorrente da escassez de moradores para a implantação e cuidado da arborização. Deste modo, incentivos na implantação de arborização de vias e praças públicas é uma das soluções para equilibrar o desconforto causado pela urbanização.

Em relação à composição florística, identificou-se 62 gêneros botânicos e 58 espécies arbóreas e arbustivas, distribuídas em 32 famílias botânicas. As famílias mais representativas foram Fabaceae e Bignoneaceae, com 24,14\% e 10,34\% respectivamente. As demais famílias possuem frequência menor que $10 \%$.

Nota-se que as três primeiras espécies na Tabela 1 estão com percentuais superiores em relação as demais. A espécie Azadiractha indica, conhecida popularmente como Neem Indiano foi a que apresentou maior percentual entre todas as espécies inventariadas nas vias da cidade, com 30,73\%. Esta mesma espécie progressivamente vem tomando espaço das áreas urbanas em diferentes regiões do país, com destaque indesejável para a região nordeste, (SOUZA et al., 2013; EDSON-CHAVES et al., 2019), região esta que abriga o maior percentual da área total do semiárido brasileiro.

Segundo Lucena et al. (2015) a espécie $A$. indica possui grande potencial de adaptabilidade e crescimento rápido, o que lhe proporciona características favoráveis no desenvolvimento no meio urbano, visto que a produção de sombreamento pela espécie se dá em curto espaço de tempo. Todavia, é uma espécie não recomendada para uso na arborização urbana, uma vez que a mesma é exótica invasora.

Tabela 1. Espécies ocorrentes nas vias da cidade de Araçuaí, com seus respectivos nomes científicos e populares, família botânica, origem e quantidade em percentual

Table 1. Species occurring on the roads of the city of Araçuaí, with their respective scientific and popular names, botanical family, origin and quantity in percentage

\begin{tabular}{|c|c|c|c|c|c|}
\hline Espécie - Nome científico & Nome vernacular & Família & Origem & $\left(\mathrm{N}^{\circ}\right)$ & $(\%)$ \\
\hline Azadirachta indica A. Juss & Neem & Meliaceae & Exótica & 335 & 30,73 \\
\hline Licania tomentosa (Benth) Fritsch & Oiti & Chrysobalanaceae & Nativa & 266 & 24,4 \\
\hline Caesalpina peltophoroides Benth & Sibipiruna & Fabaceae & Nativa & 135 & 12,39 \\
\hline Ficus benjamina $\mathrm{L}$. & Ficus & Moraceae & Exótica & 38 & 3,49 \\
\hline Murraya paniculata L. & Murta & Myrtaceae & Exótica & 35 & 3,21 \\
\hline Handroanthus spp. & Ipê & Bignoniaceae & - & 27 & 2,48 \\
\hline Bauhinia forficata Link. & Pata de Vaca (branca) & Fabaceae & Nativa & 22 & 2,02 \\
\hline Bauhinia variegata $L$. & Pata de Vaca (rosa) & Fabaceae & Exótica & 19 & 1,74 \\
\hline
\end{tabular}




\begin{tabular}{|c|c|c|c|c|c|}
\hline Espécie - Nome científico & Nome vernacular & Família & Origem & $\left(\mathbf{N}^{\circ}\right)$ & $(\%)$ \\
\hline Schinus molle L. & Aroeira-salsa & Anacardiaceae & Nativa & 17 & 1,56 \\
\hline Arrabidaea bahiensis (Schauer ex DC.) & Canelão & Bignoniaceae & Nativa & 11 & 1,01 \\
\hline Psidium guajava L. & Goiabeira & Myrtaceae & Nativa & 9 & 0,83 \\
\hline Delonix regia (Hook.) Raf. & Flamboyant & Fabaceae & Exótica & 9 & 0,83 \\
\hline Albizia lebbeck (L.) Benth. & Albizia & Fabaceae & Exótica & 9 & 0,83 \\
\hline Mangifera indica $\mathrm{L}$. & Mangueira & Anarcadiaceae & Exótica & 8 & 0,73 \\
\hline Plumeria obtusa L. & Jasmin & Apocynaceae & Exótica & 8 & 0,73 \\
\hline Roystonea oleracea (Jacq.) O. F. Cook. & Palmeira imperial & Arecaceae & Exótica & 7 & 0,64 \\
\hline Tecoma stans (L.) Juss ex. Kenth & Ipê-mirim & Bignoniaceae & Exótica & 6 & 0,55 \\
\hline Cocus sp. & Coqueiro & Arecaceae & - & 6 & 0,55 \\
\hline Erythrina indica-picta (L.) B. \& M. & Brasileirinho & Fabaceae & Exótica & 6 & 0,55 \\
\hline Muntingia calabura L. & Calabura & Muntingiaceae & Exótica & 5 & 0,46 \\
\hline Ligustrum sp. & Escumilha & Oleaceae & Exótica & 5 & 0,46 \\
\hline Adenanthera pavonina $\mathrm{L}$. & Carolina & Fabaceae & Exótica & 4 & 0,37 \\
\hline Carica -papaya L. & Mamão & Caricaceae & Exótica & 4 & 0,37 \\
\hline Anacardium occidentale L. & Cajueiro & Anarcadiaceae & Nativa & 3 & 0,28 \\
\hline Citrus limon (L.) Burm. F. & Limoeiro & Rutaceae & Exótica & 3 & 0,28 \\
\hline Citrus sinensis (L.) Osbeck. & Laranjeira & Rutaceae & Exótica & 3 & 0,28 \\
\hline Leucaena leucocephala (Lam.) de Wit. & Leucena & Fabaceae & Exótica & 2 & 0,18 \\
\hline Cassia fistula $\mathrm{L}$. & Chuva-de-ouro & Fabaceae & Exótica & 2 & 0,18 \\
\hline Magnolia sp. & Magnólia & Magnoliaceae & - & 2 & 0,18 \\
\hline Morinda citrifolia L. & Noni & Rubiaceae & Exótica & 2 & 0,18 \\
\hline Averrhoa bilimbi L. & Biri-biri & Oxalidaceae & Exótica & 2 & 0,18 \\
\hline Terminalia catappa L. & Amendoeira & Combretaceae & Exótica & 2 & 0,18 \\
\hline Punica granatum $\mathrm{L}$. & Romãzeira & Lythraceae & Exótica & 2 & 0,18 \\
\hline Hibiscus rosa-sinensis L. & Hibisco & Malvaceae & Exótica & 2 & 0,18 \\
\hline Duranta erecta L & Pingo-de-ouro & Verbenaceae & Exótica & 2 & 0,18 \\
\hline Nerium oleander $\mathrm{L}$. & Oleandro & Apocynaceae & Exótica & $\overline{1}$ & 0,09 \\
\hline Commiphora leptophloeos (Mart.) J.B.Gillet. & Emburana & Burseraceae & Nativa & 1 & 0,09 \\
\hline Ficus carica L. & Figueira-comum & Moraceae & Exótica & 1 & 0,09 \\
\hline Handroanthus heptaphyllus (Vell.) & Ipê-rosa & Bignoniaceae & Nativa & 1 & 0,09 \\
\hline Tamarindus indica $\mathrm{L}$. & Tamarindo & Fabaceae & Exótica & 1 & 0,09 \\
\hline Handroanthus albus (Cham.) Mattos) & Ipê-amarelo & Bignoniaceae & Nativa & 1 & 0,09 \\
\hline Enterolobium contortisiliquum (Vell.) & Tamboril & Fabaceae & Nativa & 1 & 0,09 \\
\hline Inga sp. & Ingá & Fabaceae & - & 1 & 0,09 \\
\hline Parkinsonia aculeata L. & Cina Cina & Fabaceae & Exótica & 1 & 0,09 \\
\hline Bougainvillea spectabilis Willd. & Primavera & Nyctaginaceae & Nativa & 1 & 0,09 \\
\hline Thuja occidentalis $\mathrm{L}$. & Pinheiro & Cupressaceae & Exótica & 1 & 0,09 \\
\hline Pachira aquatica Aubl. & Mongubeira & Bombaceae & Nativa & 1 & 0,09 \\
\hline Persea americana Mill. & Abacateiro & Lauraceae & Exótica & 1 & 0,09 \\
\hline Juglans regia L. & Nogueira comum & Juglandaceae & Exótica & 1 & 0,09 \\
\hline Yucca gloriosa L. & Yucca & Asparagaceae & Exótica & 1 & 0,09 \\
\hline Moringa oleifera Lam. & Moringa & Moringaceae & Exótica & 1 & 0,09 \\
\hline Trichilia emetica Vahl. & Mafurreira & Meliaceae & Exótica & 1 & 0,09 \\
\hline Malpighia emarginata Sesse \& Moc. ex DC. & Aceroleira & Malpighiaceae & Exótica & 1 & 0,09 \\
\hline Genipa americana L. & Jenipapeiro & Rubeaceae & Exótica & 1 & 0,09 \\
\hline Rosa spp. & Roseira & Rosaceae & Exótica & 1 & 0,09 \\
\hline Morus sp. & Amoreira & Moraceae & Exótica & 1 & 0,09 \\
\hline Acer platanoides $\mathrm{L}$. & Bordo & Sapindaceae & Exótica & 1 & 0,09 \\
\hline Annona squamosa $\mathrm{L}$. & Fruta-pinha & Anonaceae & Exótica & 1 & 0,09 \\
\hline Paubrasilia echinata Lam. & Pau Brasil & Fabaceae & Nativa & 1 & 0,09 \\
\hline Jacaranda sp. & Jacarandá & Bignoniaceae & - & 1 & 0,09 \\
\hline Eucalyptus spp. & Eucalipto & Myrtaceae & Exótica & 1 & 0,09 \\
\hline Butia arenicola (Barb Rodr.) Burret. & Coqueirinho & Arecaceae & Nativa & 1 & 0,09 \\
\hline Indivíduos não identificados & - & - & - & 45 & 4,13 \\
\hline Total & 62 espécies & 32 famílias & - & 1090 & 100 \\
\hline
\end{tabular}

A espécie Licania tomentosa (Oiti), com $20,40 \%$, obteve um percentual expressivo e preocupante, assim como o Neem, pois Segundo Miller et al. (2015), em um planejamento da arborização urbana adequado cada espécie não deve ultrapassar $15 \%$ da totalidade da 
população arbórea. O uso demasiado do Oiti na arborização urbana do país é recorrente, devido ao seu grande porte, copa frondosa, manejo simples e de fácil adaptabilidade climática.

Ao se observar a frequência das espécies mais plantadas em Araçuaí (Neem, Oiti e Sibipiruna), fica evidente a desproporcionalidade em relação ao percentual recomendado por Miller et al, (2015), com valores semelhantes a outras cidades do Semiárido Brasileiro. As 5 espécies mais plantadas em Santa Helena-PB somados os percentuais, correspondem a 91,80\% (ZEA, et al.,2015), já em Lavras de Mangabeira-CE, 94,78\% (CALIXTO JÚNIOR; SANTANA; LIRA FILHO, 2009). Na cidade de Araçuaí as 5 espécies mais representativas (Neem, Oiti, Sibipiruna, Ficus e Murta) correspondem a $74,22 \%$ da totalidade, o que evidencia o uso demasiado de algumas espécies em detrimento de outras.

Seguindo o padrão de Miller et al. (2015), a espécie Caesalpina peltophoroides Benth. (Sibipiruna) se encontra com percentual aceitável, com 12,39\%. Entretanto, o monitoramento da Sibipiruna se faz necessário na cidade, visto que a perspectiva é de aumento no seu percentual devido ao seu potencial paisagístico (BERNARDES et al., 2019), além de rápido crescimento (BOHM et al., 2017) e caso haja este aumento, irá influenciar de forma negativa na biodiversidade das espécies da arborização urbana.

Em pesquisa realizada na cidade de Araçuaí-MG por Santos e Santos (2018) as 5 espécies mais representativas são as mesmas encontradas neste trabalho, com diferença nos percentuais. Essa flutuação nos valores pode ser explicada pela diferença entre os métodos de inventário adotados, sendo este de maior espacialização.

Em relação a origem das espécies identificadas, 74,14\% são exóticas, o que corrobora com Santos e Santos (2018) onde afirmam que 70\% das espécies da cidade são exóticas. No Brasil, é comum que a característica mais importante para escolher uma espécie para a arborização seja a questão estética somente, não levando em consideração outro fator importante que é a sua origem.

Embora a cidade de Araçuaí esteja inserida em uma região de ecótono que abrange três biomas, ressalta-se que a região possui suas próprias características naturais de vegetação, estando presente também uma fitofisionomia da Mata Atlântica, a Mata Seca, bem como a predominância do bioma Caatinga e Cerrado, a depender da topografia do relevo e tipo de solo. Dessa forma, mesmo que uma espécie inventariada neste trabalho tenha recebido classificação de "nativa", pode ser natural de um dos três biomas citados e também não ser indicada para seu uso na arborização urbana da cidade.

Ao observar a Figura 4, é possivel analisar que os percentuais de espécies nativas brasileiras em relação ao seu domínio fitogeográfico tende a um cenário desfavorável, visto que mais da metade (53\%) das espécies são do bioma da Mata Atlântica, o qual ocupa o menor percentual da delimitação do Semiárido brasileiro. Dados opostos comparados a Caatinga, 
indicam que apenas $13,5 \%$ das espécies nativas são oriundas deste, embora seja o bioma que compreende a maior parte do Semiárido Brasileiro.

Isso pode ser explicado pelo fato de que as espécies da Mata Atlântica possuem indivíduos arbóreos com folhas perenes, ou seja, que não se desprendem da planta durante o período de estiagem, o que faz deste um atributo apreciado na arborização urbana. Neste trabalho por exemlo, a espécie L. tomentosa, a qual é nativa da Mata Atlântica, apresentou pouco mais de $24 \%$ da totalidade das espécies plantadas em Araçuaí, o que evidencia o uso desta, devido ao atributo da perenidade das folhas.

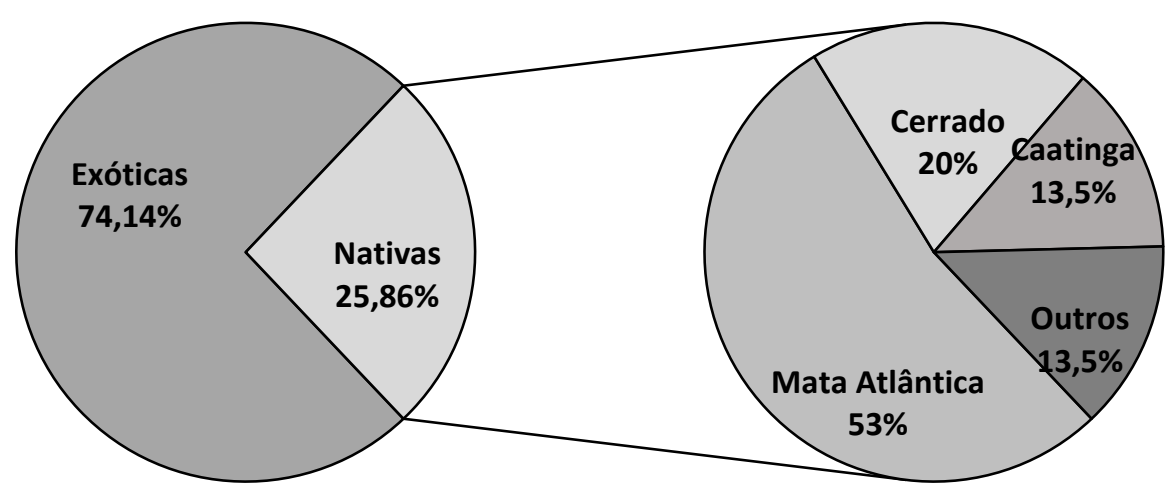

Figura 4. Origem das espécies amostradas na arborização urbana de Araçuaí, com enfoque das espécies nativas sobre a ocorrência nas principais regiões fitogeográficas que compõe o Semiárido

Figure 4. Origin of the species sampled in the urban afforestation of Araçuaí, focusing on native species on the occurrence in the main phytogeographic regions that make up the Semi-Arid

Santos e Santos (2018) indicaram em seu trabalho as espécies nativas da região que possuem potencial para serem usadas na arborização da cidade (Tabela 2). Ainda segundo as autoras, as espécies possuem características que as fazem serem ideais para seu uso, tais como: capacidade de sombreamento, beleza da espécie, porte, altura da copa e o sistema radicular. Ressalta-se o fato de as espécies nativas possuirem boa adaptabilidade ao clima semiárido da cidade, bem como prezar pela diversidade da flora regional.

Tabela 2. Relação das espécies nativas indicadas para uso na arborização de Araçuaí Table 2. List of native species indicated for use in Araçuaí afforestation

\begin{tabular}{lll}
\hline \multicolumn{1}{c}{ Nome científico } & \multicolumn{1}{c}{ Nome vernacular } & Família \\
\hline Peltophorum dubium (Spreng.) Taub. & Acari & Fabaceae \\
Andira anthelmia (Vell.) J.F.Macbr & Angelim & Fabaceae \\
Tabebuia aurea (Silva Manso) Benth.\& Hook. & Craibera & Bignoniaceae \\
Cardiopetalum calophyllum Schltdl. & Embira-branca & Annonnaceae \\
Senna macranthera (DC.exCollad.) & Fedegoso & Fabaceae \\
Handroanthus chrysotrichus (Mart.ex A. DC.) & Ipê-amarelo-do-cerrado & Bignoniaceae \\
Tabebuia roseo alba (Ridl.) Sandwith & Ipê-branco & Bignoniaceae \\
Zeyheria tuberculosa (Vell.) Bureau & Ipê-tabaco & Bignoniaceae \\
Goniorrhachis marginata Taub. & Itapicuru & Fabaceae \\
Jacaranda cuspidifolia Mart. & Jacaranda-de-minas & Bignoniaceae \\
Curatella americana L. & Lixeira & Dilleniaceae
\end{tabular}




\begin{tabular}{ll} 
Xylopia aromatica (Lam.) Mart. & Pimenta-de-macaco \\
Xylopia sericea A.St.Hil. & Pindaíba \\
Pterodon emarginatus Vogel & Sucupira-branca \\
Bowdichia virgilioides Kunth & Sucupira-preta \\
Himatanthus sucuuba (Spruce ex Mull.Arg.) & Sucuuba \\
\hline
\end{tabular}

Annonnaceae Annonnaceae

Fabaceae

Fabaceae

Apocynaceae

Fonte: Santos e Santos (2018).

Das 16 espécies recomendadas por Santos e Santos (2018), somente os ipês (gênero Handroanthus sp.) foram encontrados neste trabalho. O que corrobora com o baixo percentual $(30,65 \%)$ de espécies nativas inventariadas que estão presentes na cidade.

\section{Aspectos quali-quantitativos - Primários}

A altura total dos invidíduos em cada setor pode ser observada na Figura 5, em que sete dos nove setores apresentam $50 \%$ ou mais de indivíduos com altura total inferior a 6 metros, o que evidencia que a maioria dos indivíduos da cidade são jovens ou foram podados. O setor S9 é o único que possui em sua maioria indivíduos com altura entre 6 - 10 metros $(36,49 \%)$, que neste trabalho são considerados de porte médio, o que pode ser explicado pelo fato desse setor ser composto pelo bairro Santa Tereza, considerado um bairro antigo e por consequência uma arborização com indivíduos mais desenvolvidos, além ser um bairro com alto valor agregado no mercado imobiliário da cidade.

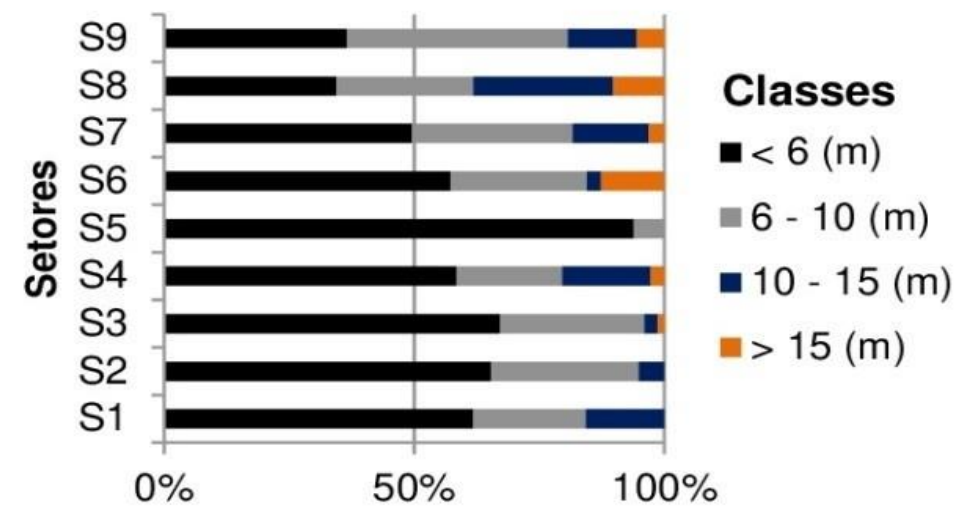

Figura 5. Distribuição dos setores com seus respectivos percentuais do aspecto da Altura total Figure 5. Distribution of sectors with their respective percentages of the total height aspect

Nota-se que as alturas superiores a 10 metros foram as que obtiveram os menores percentuais no geral, sendo a classe entre 10 e $15 \mathrm{~m}$ com valores que variam de $2 \%$ a $30 \%$ e a classe maior que $15 \mathrm{~m}$ valores de $1 \%$ a 14\%. Naturalmente, valores altos de CAPs indicariam indivíduos de maior idade e altura. Entretanto, neste trabalho, a Figura 6 apresenta o contrário. Menor altura e maior o valor de CAP, que influi que a cidade possui uma arborização que sofre podas regulares, de modo que impede um maior desenvolvimento vertical dos indivíduos. 


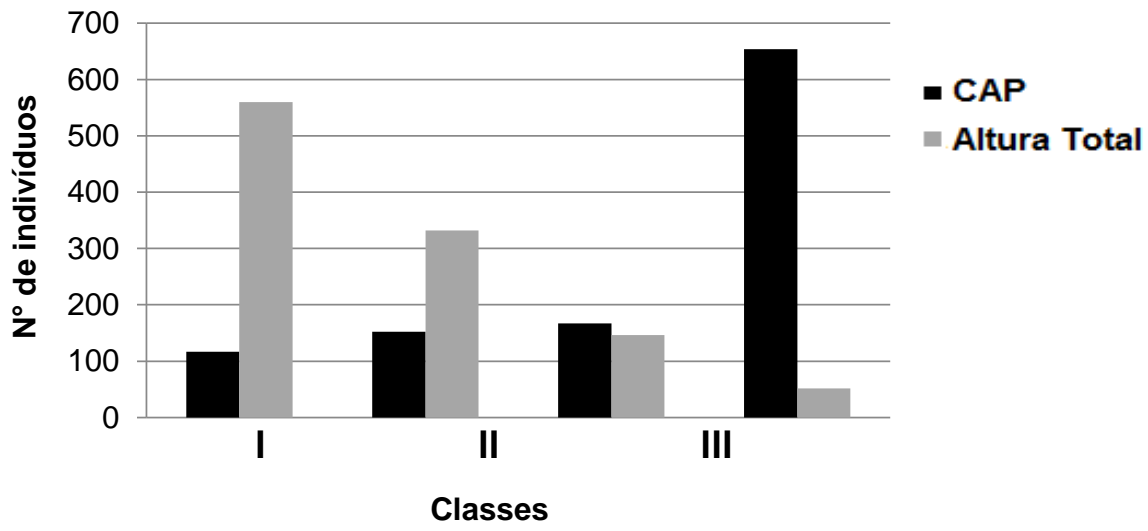

Figura 6. Comparação entre os valores dos aspectos de CAP e Altura Total (At) dos indivíduos plantados em Araçuaí dados em classes: I: CAP < $15(\mathrm{~cm})$ e AT $<6(\mathrm{~m})$, II: CAP $15-30(\mathrm{~cm})$ e AT $6-$ $10(\mathrm{~m})$, III: CAP $30-45(\mathrm{~cm})$ e AT $10-15(\mathrm{~m})$, IV: CAP > $45(\mathrm{~cm})$ e AT > $15(\mathrm{~m})$

Figure 6. Comparison between the values of the CAP and Total Height (AT) aspects of individuals planted in Araçuaí in data classes: I: CAP $<15(\mathrm{~cm})$ and AT $<6(\mathrm{~m})$, II: CAP $15-30(\mathrm{~cm})$ and AT 6 - $10(\mathrm{~m})$, III: CAP $30-45(\mathrm{~cm})$ and AT $10-15(\mathrm{~m})$, IV: CAP> $45(\mathrm{~cm})$ and AT> $15(\mathrm{~m})$

Com relação ao estado fitosanitário (Figura 7), observa-se que a maioria dos setores apresentam classe de estado da fitossanidade dos indivíduos considerado "boa", com exceção dos setores S2 e S8, os quais essa classificação é inferior a 50\%. Todos os setores apresentam percentuais de indivíduos com estado "regular". Além disso, o estado "ruim" se faz presente em oito dos nove setores, o que destaca a necessidade de uma maior atenção para este aspecto, podendo incluir no monitormento a incidência dos tipos de doenças e pragas sobre os indivíduos. Somente dois setores (S3 e S9) apresentaram casos de indivíduos mortos, com percentuais pouco expressivos.

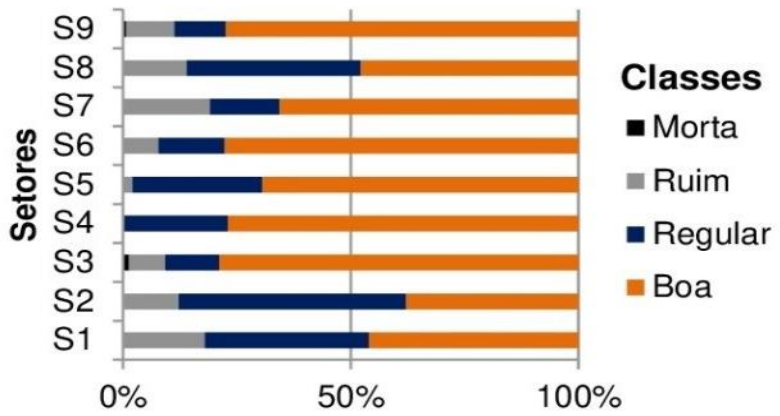

Figura 7. Distribuição dos setores com seus respectivos percentuais do aspecto da Fitossanidade Figure 7. Distribution of sectors with their respective percentages of the Phytosanitary aspect

Ao analisar a fiação conflitante (Figura 8), podem ser vistos percentuais consideráveis de que não possui rede elétrica em conflito, resultado positivo, pois diminui os riscos a vida humana e animal, além de potencializar o uso de espécies de maior porte. Entretanto, todos os nove setores apresentaram algum percentual relativo quanto a fiação no meio da copa. As podas 
inadequadas podem estar relacionadas com esse fato. Neste trabalho, embora nenhum setor ultrapasse 50\%, destacam-se os setores S6, S7, S8 e S9, que apresentam percentuais entre 20 e $45 \%$ de indivíduos em conflito com a fiação local, o que implica na priorização das possíveis tomadas de decisão para com estes setores.

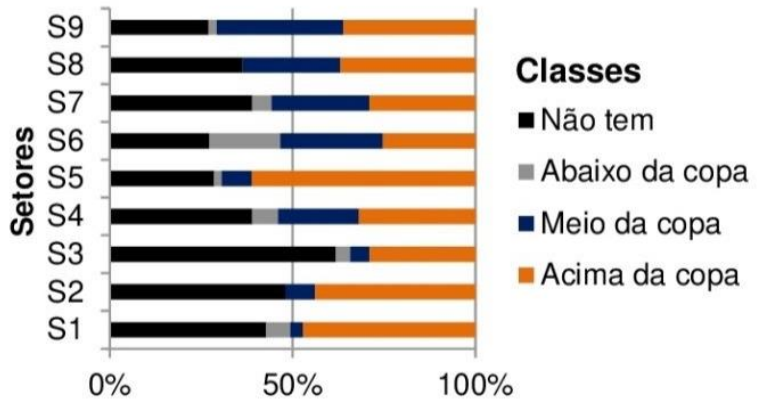

Figura 8. Distribuição dos setores com seus respectivos percentuais do aspecto da Fiação Figure 8. Distribution of sectors with their respective percentages of the spinning aspect

Em relação a necessidade de poda (Figura 9), os setores apresentaram valores que variaram entre $20 \%$ e $80 \%$ da "não necessidade de poda", destaque para os setores S1, S4 e S5 com taxas acima dos 50\%. Entretanto, embora estes percentuais aparentam ser positivos (positivo pois não será preciso executar nenhuma ação mitigadora em relação a este aspecto), ressalta-se que grande quantidade de indivíudos apresentavam ter sofrido podas drásticas anterior a realização do inventário, o que explica os altos percentuais em relação a "não necessidade de poda".

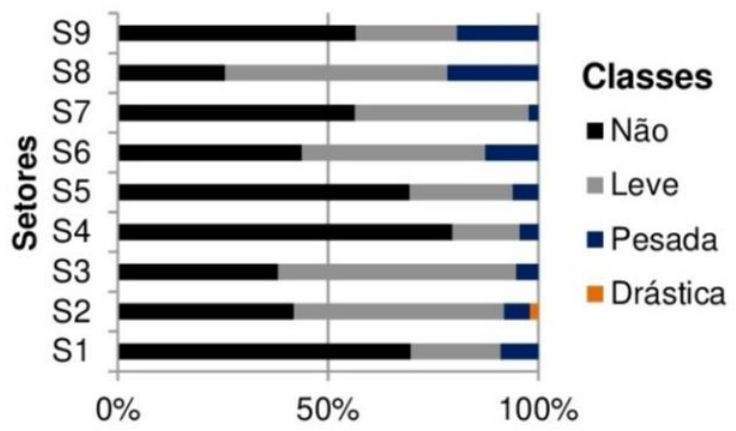

Figura 9. Distribuição dos setores com seus respectivos percentuais do aspecto da Necessidade de poda Figure 9. Distribution of sectors with their respective percentages of the Pruning Needs aspect

Em contrapartida, a necessidade de poda leve também se faz presente em todos os setores, com percentuais que variam entre $15 \%$ e 60\%, destacando-se os setores S2, S3 e S8, com valores igual ou acima de $50 \%$. Entretanto, embora os percentuais de necessidade de poda pesada não ultrapassarem $25 \%$, todos os setores possuem essa necessidade. Somente o setor 
S2 possui indivíduos com necessidade de poda drástica, com pouco mais de $2 \%$. Ressalta-se a importância da realização de podas de acordo a necessidade de cada indivíduo.

\section{Aspectos quali-quantitativos - Secundários}

Em relação a infraestrutura e mobilidade urbana dos pedestres (Figura 10A), é evidente que os setores com os maiores percentuais de inexistência de passeio são compostos em sua maioria por bairros novos e/ou subdesenvolvidos da cidade, os quais já possuem as menores taxas de densidade florística. A Lei Municipal 08/2007 que dispõe sobre o parcelamento, uso e ocupação do solo no município de Araçuaí, diz que vias de ligação regional e arteriais devem possuir ao menos 4 metros de largura e as demais vias, mínimo de 3 metros.

Entretanto, cinco setores apresentaram percentuais expressivos da largura inferior a 1,5 metros (S2, S3, S4, S5 e S7) assim como as larguras entre 1,5 metros e 3,0 metros que obtiveram percentuais expressivos em vários setores (S5, S7 e S9), o que é negativo, visto que não atigem a largura recomendada pela Lei Municipal. Para larguras de passeio maiores que 3,0 metros, houve uma maior heterogeneidade entre os setores, destaque para o setor S8 que obteve um percentual significativo $(36,14 \%)$.
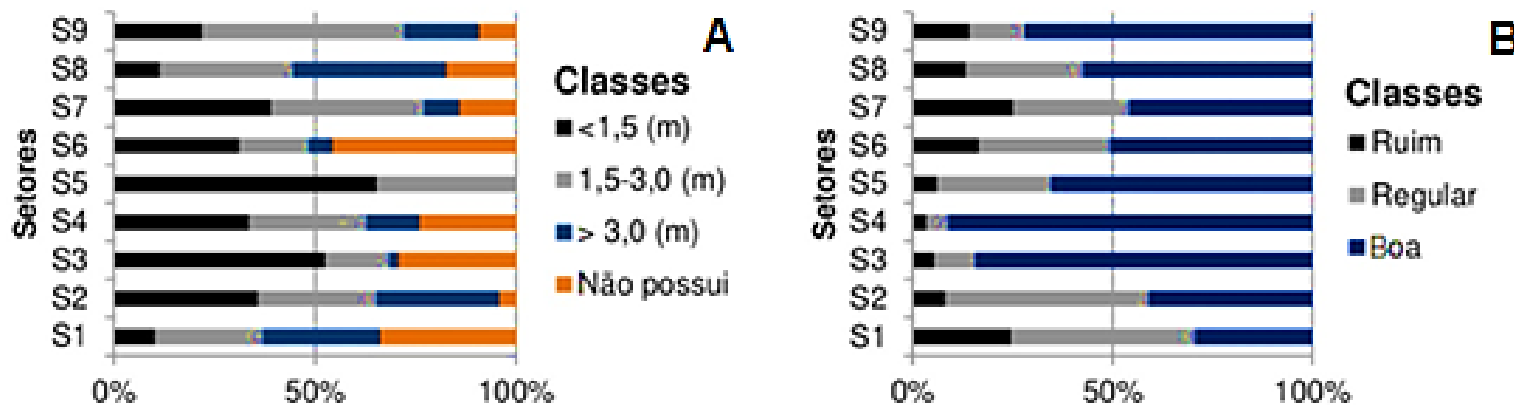

Figura 10. Distribuição dos setores com seus respectivos percentuais do aspecto da Largura do passeio (A) e Condição da raiz (B)

Figure 10. Distribution of sectors with their respective percentages of the Sidewalk width $(A)$ and Root condition (B)

O aspecto condição da raiz (Figura 10B) apresentou no geral resultados satisfatórios, tendo em vista que há predominâcia em todos os setores, de percentuais expressivos relativos a classes de "Boa" e "Regular". Com excessão dos setores S1, S2 e S7, todos os demais sobressairam com percentuais de "boa condição", acima de 50\%. Os setores S1 e S2 podem ser classificados como condição da raiz "regular a ruim", o que faz estes setores serem prioridade para regularização do aspecto em discussão, visto que interfere diretamente na acessibilidade das pessoas.

Em relação a circunferência a altura do peito (CAP) (Figura 11A) nota-se que na maioria dos setores predonimam circunferências acima de $45 \mathrm{~cm}$. As demais classes aparecem de forma 
heterogênea em menores percentuais entre os setores. Para Souza et al., (2014), o CAP está ligado com a altura dos indivíduos. Dessa forma, os valores menores que $45 \mathrm{~cm}$ podem indicar que os invidíduos arbóreos são jovens, como é o exemplo dos setores S1, S2 e S6. Esse grupo possui características semelhantes de bairros jovens e em processo de desenvolvimento urbanístico, o que pode explicar a juventude dos indivíduos.
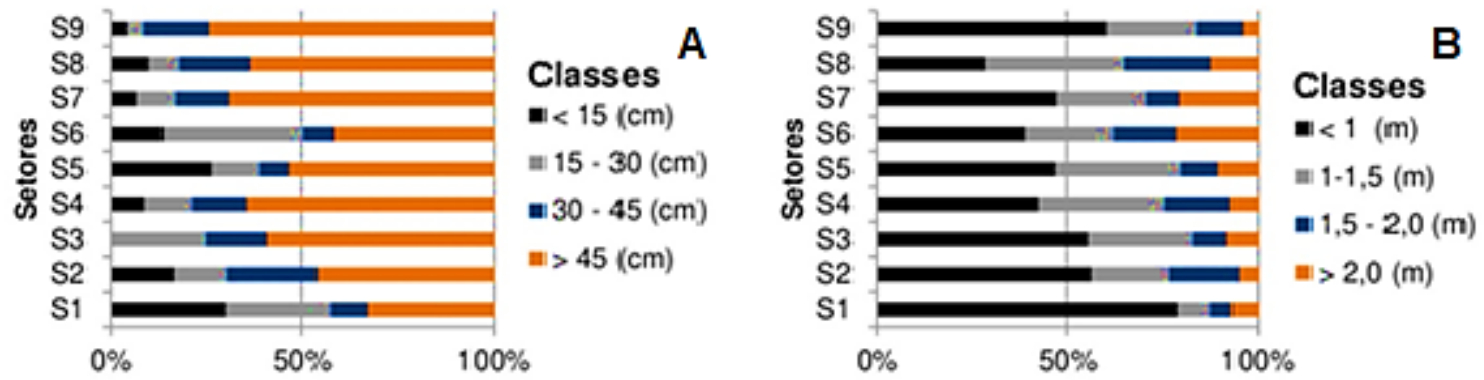

Figura 11. Distribuição dos setores com seus respectivos percentuais do aspecto da Circunferência altura do peito (CAP) (A) e Altura da primeira bifurcação (B)

Figure 11. Distribution of the sectors with their respective percentages of the Circumference at Breast Height (CBH) (A) and Height of the first bifurcation (B)

O aspecto Altura da primeira bifurcação (Figura 11B) apresentou resultados insatisfatórios com base na altura considerada ideal, que é de 2 metros entre o solo e a primeira bifurcação, onde pedestres podem transitar com facilidade nos passeios (MELO; LIRA FILHO; RODOLFO JÚNIOR, 2007). Em trabalho realizado na cidade de Rio Branco - AC pelos autores acima, apenas $20 \%$ dos indivíduos apresentaram a altura ideal e, isso pode indicar o manejo inadequado na condução dos indivíduos, sobretudo na fase jovem. Neste trabalho, a altura ideal não alcançou mais que $25 \%$ em nenhum dos setores, resultado semelhante ao trabalho citado anteriormente, que pode ser considerado negativo.

Os aspectos de Avanço da copa sobre a rua (Figura 12A) e Avanço da copa sobre a construção (Figura 12B) apresentaram bons resultados. No primeiro é possível observar que a maioria dos setores (S1, S2, S3, S4, S6, S7 e S9) se caracterizam por possuírem copa com avanço menor que 1,5 metros em relação à rua.
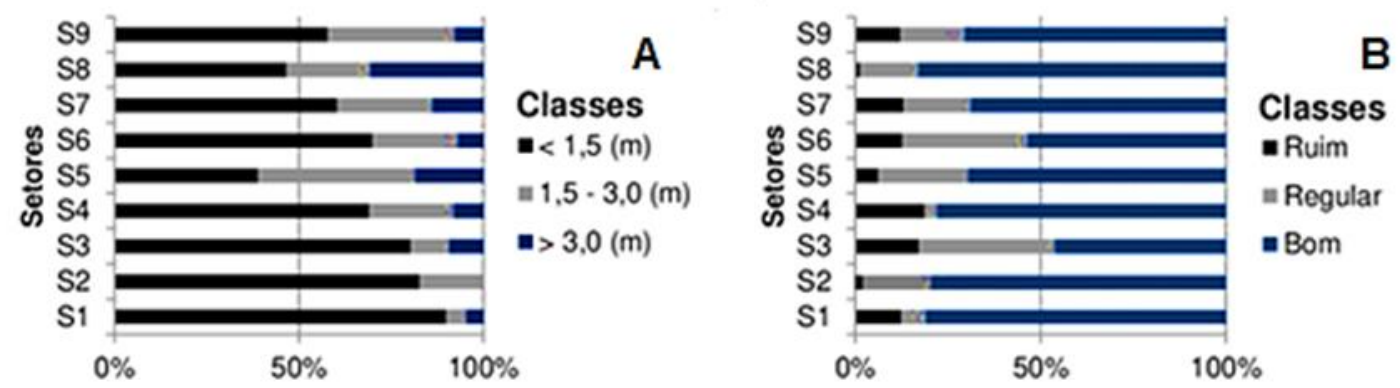

Figura 12. Distribuição dos setores com seus respectivos percentuais do aspecto do Avanço da copa sobre a rua (A) e Avanço da copa sobre a construção (B)

Figure 12. Distribution of sectors with their respective percentages of the canopy over the street $(A)$ and canopy over the construction (B) 
No entanto, os setores S5 e S8 requerem atenção, pois as classes entre 1,5 metros e 3,0 metros se destoam dos demais, situação não propícia para o deslocamento de pedestres e veículos automotores nas ruas. Já o Avanço da copa sobre a construção pode ser classificado no geral como "bom", onde oito dos nove setores possuem ao menos $50 \%$ dessa classificação. Entretanto, todos os setores apresentaram algum percentual considerado neste trabalho como negativos (Regular e Ruim).

\section{CONCLUSÕES}

A arborização de vias públicas da cidade de Araçuaí é constituída principalmente de indivíduos que sofrem podas regulares, com baixa densidade de indivíduos por quilômetro de via e baixa biodiversidade, a qual predomina três espécies principais (Neem, Oiti e Sibipiruna). Possui ainda alta relação de espécies exóticas para com as nativas. Recomenda-se a não utilização das espécies já abundantes, priorizando o uso de espécies nativas da flora regional.

No geral, os setores possuem aspectos fitossanitários satisfatórios, sem grande necessidade de podas pesadas ou drásticas, mas em todos os setores há necessidade de podas leves. Os setores compostos por bairros novos, como o São Matheus, São Francisco III e Nova Esperança foram os que apresentaram os maiores percentuais de inexistência de calçada e os menores índices de densidade florística. Para estes bairros orienta-se a criação ou ampliação de praças públicas, com o objetivo de complementar os serviços ambientais proporcionados pela arborização, além da criação de calçadas nas vias localizadas nos setores supracitados.

Em todos os setores cabem intervenções de curto, médio ou longo prazo, mas cada um deles possui um aspecto que necessita ser priorizado. De modo geral, todos os nove setores apresentaram grande variabilidade dos dados. Recomenda-se o monitoramento da incidência de pragas e doenças e estratégias de adensamento ou enriquecimento da arborização por meio do plantio de novos indivíduos. Ademais, as informações contidas neste trabalho são importantes e necessárias para auxiliar a gestão pública no planejamento e execução de intervenções para com a melhoria dos aspectos que compõem a arborização urbana da cidade.

\section{AGRADECIMENTOS}

Secretaria Municipal de Meio Ambiente de Araçuaí e Instituto Federal do Norte de Minas Gerais. 


\section{REFERÊNCIAS}

ALVARES, C. A; STAPE, J.L; SENTELHAS, P.C; DE MORAES GONÇALVES, J.L; SPAROVEK, G.. Köppen's climate classification map for Brazil. Meteorologische Zeitschrift, Stuttgart, v. 22, n. 6, p. 711-728, 2013.

ALVAREZ, I.; OLIVEIRA, U. R.; MATTOS, P. P.; BRAZ, E. M.; CANETTI, A. Arborização urbana no semiárido: espécies potenciais da Caatinga. Embrapa Florestas, Colombo, 2012.

BERNARDES, A.M.A; MOURA, T.M; DINIZ, V.S.D.S; DIAS, M.A; MARQUES, M. Levantamento florístico e fitossociológico do componente arbóreo de praças públicas do município de Iporá, Goiás. Revista Verde de Agroecologia e Desenvolvimento Sustentável, Pombal, v. 14, n.3, p.436-442, 2019.

BOHM, F.M.L.Z; PHILIPPSEN, A.S; DE OLIVEIRA, D.S; GARCETE, L.H.T; BERTOLA, P.B; BOHM, P.A.F. Emergência e crescimento de alface (Lactuca sativa L.) submetida a substratos orgânicos. Revista Verde de Agroecologia e Desenvolvimento Sustentável, Pombal, v.12, n. 2, p. 348-352, 2017.

CALIXTO JÚNIOR, J. T; SANTANA, G. M; LIRA FILHO, J.A. Análise quantitativa da arborização urbana de lavras da mangabeira, ce, nordeste do brasil. Revista da Sociedade Brasileira de Arborização Urbana, Curitiba, v. 4, n. 3, p. 99-109, 2009.

CARDOSO, K. M.; DE PAULA, A.; SANTOS, J.; SANTOS, M. L. Uso de espécies da arborização urbana no biomonitoramento de poluição ambiental. Ciência Florestal, Santa Maria,v. 27, n. 2, jun. 2017.

EDSON-CHAVES, B.; DANTAS, A. G. B.; LIMA, M. S.; PANTOJA, L. D. M.; MENDES, R. M. S. Avaliação qualiquantitativa da arborização da sede dos municípios de Beberibe e Cascavel, Ceará, Brasil. Ciência Florestal, Santa Maria, v. 29, n. 1, p. 403-416, 2019.

FLORA DO BRASIL 2020 EM CONSTRUÇÃO. Jardim Botânico do Rio de Janeiro. Disponível em: < http://floradobrasil.jbrj.gov.br/ >. Acesso em: 30 mai. 2020

IBGE- INSTITUTO BRASILEIRO DE GEOGRAFIA E ESTATÍSTICA. Pesquisa nacional por amostra de domicílios: Síntese de Indicadores. Rio de Janeiro: IBGE, 2016. 108 p.

LACERDA, R. M. A.; LIRA FILHO, J. A.; SANTOS, R. V. Indicação de espécies de porte arbóreo para arborização urbana no semi-árido paraibano. Piracicaba: Revista da Sociedade Brasileira de Arborização Urbana, Curitiba, v. 6, n. 1, p. 51-68, 2011.

LUCENA, J.N; SOUTO, P.C; CAMAÑO, J.D.Z; SOUTO, J.S; SOUTO, L.S. Arborização em canteiros centrais na cidade de Patos, Paraíba. Revista Verde de Agroecologia e Desenvolvimento Sustentável, Pombal, v. 10, n. 4, p. 20-26, 2015.

MCPHERSON, E.G, VAN DOORN, N.; DE GOEDE, J. The State of California's Street Trees. 2015, Pacific Southwest Research Station, U.S. Forest Service: Davis, CA

MELO, R. R.; LIRA FILHO, J. A.; RODOLFO JÚNIOR, F. Diagnóstico qualitativo e quantitativo da arborização urbana no bairro Bivar Olinto, Patos, Paraíba. Revista Da Sociedade Brasileira De Arborização Urbana, Curitiba, v.2, n.1, p.64-78, 2007.

MILANO, M.; DALCIN, E. Arborização de vias públicas. Rio de Janeiro: LIGHT, 2000. 226 p. 
MILLER, R. W.; HAUER, R. J., WERNER, LES, P. (2015). Urban forestry: planning and managing urban greenspaces. Waveland Press, $512 \mathrm{pp}$.

OTONI, T.C.O. Levantamento etnobotânico de plantas utilizadas com fins medicinais e cosméticos em comunidades tradicionais do município de Araçuaí, Minas Gerais. Dissertação (Mestrado em Ciências Farmacêuticas) - Universidade Federal dos Vales do Jequitinhonha e Mucuri, Diamantina, 2018.

RACHID, C.; COUTO, H. T. Z do. Estudo da eficiência de dois métodos de amostragem de árvores de rua na cidade de São Carlos - SP. Scientia Forestalis, São Carlos - SP, n.56, p. 5968, 1999.

SANTOS, A. A. A; SANTOS, A.L. Potencial de uso de espécies arbustivo-arbóreas nativas para a arborização urbana em Araçuaí. 2018. 75 f. TCC (Graduação) - Curso de Tecnologia em Gestão Ambiental, Instituto Federal do Norte de Minas Gerais, Araçuaí, 2018

SOARES, C. P. B.; DE PAULA NETO, F.; DE SOUZA, A. L. Dendrometria e inventário florestal. UFV, 2012.

SOARES, T.R; DE SOUZA, P.G; KOEHLER, A.B; RIBASKI, N. G. Estudo da percepção da população de Curitiba - PR em relação ao valor das áreas verdes. Brazilian Journal of Animal and Environmental Research, Curitiba, v. 1, n. 1, p. 134 - 167, 2018.

SOUZA, D. I. M.; DA COSTA, R. L; GURGEL, M. T; SOARES, R. F. Arborização do Bairro Peixegordo na cidade de Icapuí-Ce. Revista Verde de Agroecologia e Desenvolvimento Sustentável, Pombal, v. 8, n. 4, p. 238-243, 2013.

SOUZA, R. DE. C; AGUIAR, O. T. DE; SILVA, L.T. A. DA; SILVA, L. A; MARRA, R. C. Avaliação quali-quantitativa da arborização na praça Agostinho Nohama, Bairro Lauzane Paulista, São Paulo - sp. Revista Da Sociedade Brasileira De Arborização Urbana, Piracicaba, v.9, n.1, p.92-107, 2014.

ZEA, C.J.D; BARROSO, R.F; SOUTO, P.C; SOUTO, J.S; NOVAIS, D.B. Levantamento da arborização urbana de Santa Helena, no Semiárido da Paraíba. Agropecuária Científica no Semi-árido, Patos, v. 11, n. 3, p. 53-62, 2015. 